\title{
Dialogue-based peer learning of educational topics in a university classroom
}

\author{
Shih-Hsiung Liu
}

\begin{abstract}
This article aims to determine the feasibility of a course on educationrelated topics based on dialogue-based peer learning (DBPL). According to the literature, the procedures of DBPL are as follows: (1) read texts, (2) formulate individual opinions, (3) express individual opinions in turns, (4) ask and respond to questions, (5) adjust personal opinions. A quantitative survey, an open-ended question on learning perceptions and four paper-and-pencil tests on educational topics were employed to determine the effectiveness of the course for participants' learning. Most of the participants performed well in the tests and perceived the benefits of the DBPL method for comprehension and for critical thinking on educational topics. The first three steps in the procedure outlined above were identified as key to the results of the study.
\end{abstract}

\section{KEYWORDS}

critical thinking skills, dialogue-based peer learning, educational topics, peer discussion, sociocognitive conflict, teacher education, university teaching

Education-related topics stimulate arguments about education practices. When educators adopt partial opinions, they can incorrectly judge educational practices. I am an educator and my students will graduate as certified teachers; these students are expected to comprehend education-related topics deeply. According to the perspectives of social constructivism, a shared understanding among individuals not only provides the basis for communication but also aids them in comprehending new information (Rogoff 1990; Vygotsky 1978). Teacher education students who undertake dialogue-based learning for education-related topics may potentially develop a more profound understanding than students who do not. 
Dialogue-based peer learning (DBPL) may be employed in many subject areas in higher education, for example, English language (Schwab 2011) and psychology (White et al. 2019). Stergios Tegos and Stavros Demetriadis (2017) indicated that students paraphrased and expanded upon each other's ideas during DBPL. When individuals extend their opinions through comparisons, critical thinking and self-regulation, they construct knowledge. Kay Sambell et al. (2017) argued that dialogue is essential to students' construction of knowledge in social learning. Through cognitive processes, learners explicate their reasoning, compare their contributions with those of their partners and construct logical evidence-based arguments (Michaels et al. 2010). Although the DBPL method enables students to construct new understandings, students might not wish to participate in DBPL activities. Several specific factors - internal and external - influence the effectiveness of DBPL. Some students may remain silent (Cantrell 2002). Moreover, many students can feel exhausted because of the emotional, cognitive and sensory overload (Andersen et al. 2018). Educators should be aware of students' perceptions about participation in DBPL activities.

The study of education-related topics enhances teacher education students' comprehension of educational practices. The DBPL method can be used to assist teacher education students develop their understandings of and opinions on education-related topics. Accordingly, I constructed a teaching framework based on DBPL for a teacher education course with the aim of improving student teachers' critical thinking skills and promoting their comprehension of education-related topics. The purpose of this study was to assess the participating students' learning performance levels and thereby determine the feasibility of the proposed teaching framework.

\section{Theoretical perspectives}

\section{The need for a framework}

A strength of DBPL is that it provides students with opportunities to incorporate their experiential knowledge into discussion, so promoting learning (Hendriks and Maor 2004). In applications of peer-learning strategies, teachers must encourage student participation and provide dynamic conversational support to ensure academically productive discussions (Sohmer et al. 2009). Additionally, the students must be accountable to their learning partners in expressing accurate information and demonstrating rigorous thinking (Sohmer et al. 2009). However, many students only offer surface-level responses during 
peer discussions (Cantrell 2002). Accordingly, a procedural framework is necessary to guide peer interactions and subsequent individual reflection.

According to Roy Killen (2000), reading and discussing texts provide an opportunity for peer dialogue (Dixon-Krauss 1995), which in turn offers a chance for students to communicate and explore both the individual and collective presuppositions, ideas and feelings that subtly influence their interactions (Bohm et al. 1991). To facilitate learning, social interactions require intentional actions from people who are willing to listen and respond to each other's opinions. Within the DBPL framework, students are encouraged to express opinions based on relevant texts, consider alternative perspectives proposed by peers and reconcile opposing points of view. During peer learning, students can help one another construct meanings and fill in each other's gaps in background information through dialogue (McMahon and Raphael 1997).

For structuring student-teacher reading discussion groups, Susan Cantrell (2002) proposed the following processes: choosing, actively reading, reacting, discussing and sharing (CARDS). Cantrell discovered that CARDS not only improved discussions, which had been inadequate before implementation of this structure, but also promoted the construction of knowledge. Jennifer Berne and Kathleen Clark (2008) developed a procedure model for arrangements of discussion groups to facilitate discussions of assigned texts. Berne and Clark subsequently reported that several meaningful dialogues occurred after the model was implemented in a classroom. For example, students asked questions, answered and responded to questions, listened carefully to other students and self-reflected by rereading the text. The learners' cognitive resources had been activated, giving rise to deep dialogues, and the desired performance outcomes. This framework is based on a combination of cognitive methods and sociocultural theory, according to which a learning situation is not static but rather is transformed as a result of cognitive changes that occur during interactions (Wood et al. 2014).

According to John Hammond et al. (2010), the structure of a framework for peer-led learning is critical. Bridges (1990) proposed the following discussion framework: (1) students must talk, (2) listen, and (3) respond to one another; (4) collectively address more than one point of view; and (5) develop their knowledge, understanding, or judgment of the topic under discussion. Additionally, according to Anna Soter et al. (2008), teachers should choose texts and arrange heterogeneous members into teams, and subsequently students should read and narrate the texts and offer comments 
and responses in turn. Therefore, teachers need to guide dialogues in DBPL and provide demonstrations of peer dialogues. As described, instructional guidance may include giving explanations of personal reasoning, developing skills in asking and responding to questions, comparing personal and partners' contributions to a discussion and constructing a logical argument.

\section{Learning changes occur during sociocognitive conflict}

An innovative idea or an extended opinion may originate within the processes of critical thinking, specifically through comparison of personal and others' viewpoints and subsequent self-regulation. Based on Jean Piaget's concept of cognitive conflict (1975), a student's cognitive structures are disrupted by inconsistent information, leading to more elaborate knowledge and cognitive gains. The disruption of the previous knowledge by a dissenting partner is called sociocognitive conflict (Doise and Mugny 1984). In peer interactions, new opinions originate from sociocognitive conflict, which is the key element of critical thinking.

Michael Scriven and Richard Paul (n.d.) identified that critical thinking is a cognitive activity that involves conceptualising, applying, analysing, synthesising and evaluating information to reach an answer or conclusion. According to Barry Beyer (1995), critical thinking refers to the process of making clear, reasoned judgments. Stephen Brookfield described critical thinking 'as seeing things from different viewpoints' (2012: 12). Mei-Yao Huang et al. (2017) identified critical thinking skills as influential factors for peer discussion and learning in college classrooms. If students lack critical thinking skills sufficient to engage in a dialogue with their peers, peer discussions may proceed through an exchange of surface-level viewpoints.

George Posner et al. (1982) indicated that for learners, cognitive conflicts are generated by dissatisfaction with existing conceptions, which motivates learners to reorganise, restructure or change their existing ideas. In social interactions, participants experience conflicts between their cognitive response and those of other participants. During peer interaction, learners may be exposed to alternative perceptions and conflicting views from peers, likely being put in such a state of sociocognitive conflict (Buchs et al. 2010; King 2002). Then, through explaining and defending their views to their group, those conflicts may be reconciled.

Generally, peer discussion is an external behaviour, whereas critical thinking is an internal mental process that may occur during peer discussion. 
Conflicting views among peers lead to sociocognitive conflicts (Mugny and Doise 1978), which lead to new perspectives. Margo Taal and Louis Oppenheimer (1989) indicated that sociocognitive conflict is likely to occur in competitive and supervised conditions. Florentina Mogonea and Alexandrina Popescu (2015) investigated the role of sociocognitive conflict in a discussion activity; the researchers determined that sociocognitive conflict helped learners understand concepts and construct their own knowledge bases through critical thinking processes. Peer dialogue may motivate students to engage in relational resolution of sociocognitive conflicts. If students perceive strong sociocognitive conflict between their and others' opinions, they can attempt to integrate the points of view (Butera and Darnon 2010). Accordingly, sociocognitive conflict in peer interactions is critical to learning outcomes.

\section{Factors that affect peer dialogue}

Jessica To and Yiqi Liu (2018) explored the characteristics of peer and teacherstudent discussions in three postsecondary education classrooms and the challenges in the dialogic process. They discovered that the students lacked the capacity to resolve sociocognitive conflicts in peer dialogue. Several specific factors influence the effectiveness of DBPL. William Guilford (2001) indicated that pre-existing knowledge of education-related topics was critical in peer dialogue. Pre-existing knowledge and reading comprehension affect learning from texts (Scheiter et al. 2014). For sociocognitive conflict to arise from conflicting views among peers and help learners deepen in their understanding of the peer discussion topics, the learners must have generated their own perspectives before engaging in the discussion. Without the involvement of pre-existing individual perspectives in peer discussions, sociocognitive conflict is limited or does not occur, resulting in poor DBPL outcomes.

Students might not participate in discussions with neighbours if they lack motivation (Chou and Lin 2015). Students' motivation to participate in discussions should also be considered during the implementation of DBPL. Teachers should do their best to ensure that students are motivated to engage in peer dialogue. Students respond to course designs and opportunities for peer dialogue based on their intrinsic and extrinsic motivations (Ryan and Deci 2000). Intrinsic motivation refers to 'doing something because it is inherently interesting or enjoyable’ (Ryan and Deci 2000: 55), and extrinsic motivation refers to 'doing something because it produces a separable outcome' (Ryan and Deci 2000: 55). Additionally, tangible rewards considerably affect 
peer discussions (Ding et al. 2018). In sum, discussion topics that are engaging and challenging but not too difficult and extrinsic rewards for learners' performance levels may enhance peer dialogue on educational topics. Furthermore, partner assignments can promote student discussions by generating positive interdependence among students (Chou and Lin 2015). When partners are assigned, students lacking motivation to converse with peers are approached by their assigned discussion partner(s), and thus may be encouraged to engage in the discussion.

The perspectives from the literature on discussion-based learning were used to guide the design of the instructional framework and to identify the potential problems of DBPL. Dialogue procedure, student motivation, and partner assignment were all considered in the design of the teaching activity. Additionally, topics that can stimulate various perspectives and teachers' guidance in critical thinking processes can enhance the effectiveness of DBPL activities.

\section{Data Collection}

\section{Participants}

This study was conducted with students enrolled in an elective teacher education course called 'Curriculum Development and Design' at a university in Central Taiwan. Because curriculum ideologies play a significant role in curriculum development and design, these discourses were properly the core of the teaching activities in the course and formed the basis for the discussion questions. Education-related topics offer numerous interpretations depending on educational issues being discussed, so the perspectives of students who pursue educational studies are likely to differ. Education-related topics may trigger a sociocognitive conflict among students during peer discussions. For this reason, the course was suitable for employing DBPL activities. In total, 115 students attended the course from September 2017 to January 2018. Of these students, 35 were males ( 30.4 per cent) and 80 were females (69.6 per cent). Additionally, 82 of the participants were undergraduates (71.3 per cent), and 33 were graduate students (28.7 per cent).

Because the course presented advanced topics, teacher education students were encouraged to elect the course only after completing courses in specific basic disciplines. According to Guilford (2001) and Scheiter et al. (2014), preexisting knowledge and reading comprehension affect learning from texts. Any problems regarding pre-existing knowledge cannot be examined before 
the course begins because the education-related topics of the course demonstrate multiple and uncertain perspectives. Because the students had completed courses in specific basic disciplines, they were assumed to have basic knowledge that they could apply in discussions of the educational topics. Nevertheless, some participants may not have had sufficient basic knowledge due to gaps in their learning outcomes from their previous courses. The problem of pre-existing knowledge is discussed in the following section.

\section{Instruction design}

\section{Selection of education-related topics}

The questions of the education-related topics were developed and edited according to the core information in each lesson as well as standards for engagingness and potential to motivate discussion. The lessons completed in the course were on diversity of curriculum ideology, models of curriculum development, models of curriculum design, choices of curriculum objective, organisation of curriculum content, origination of curriculum programmes, processes of curriculum implementation, and perspectives of curriculum evaluation. An example of the lesson design and education-related topic is as follows.

In the lesson that addressed diversity of curriculum ideology, a discussion question about curriculum ideology in currently used textbooks was proposed. The discussion question used in the lesson was: 'The description of the first article in a textbook presents a paragraph regarding the benefits of a specific government policy proposed by the ruling party. The images of the second article show a father weeding the garden outdoors and a mother cooking dinner in the kitchen. What is your opinion about the two articles?' In Taiwan, the sociocultural context for various ideologies differs from that of the ideologies in Western societies; this sociocultural context affects the opinions of Taiwanese teachers regarding social topics. Thus, the curriculum ideology of Taiwanese textbooks is an engaging topic for teacher education students.

\section{Implementation of the DBPL}

In the first week of the course, I explained the concept of DBPL and described the method of partner assignment. Participants were asked to discuss the education-related topics after the lectures of each lesson from the sixth to the thirteenth week. In total, eight discussion activities were held over eight 
weeks. Each DBPL activity involved only one education-related topic. After presenting the education-related topics for each DBPL activity, I explained the associated discussion question. I did not offer my own opinions, because I wanted to avoid influencing the students' thoughts on the topic. After the activity, I usually encouraged the participants to reflect on the initial thoughts they experienced when listening to their partners' opinions on the education-related topic.

Guidance about peer dialogue was based on the work of Bridges (1990). The procedures for DBPL were as follows: (1) read the education-related material and the subsequent questions, (2) formulate individual opinions without any dialogue, (3) express individual opinions to peers in turn, (4) ask and respond to questions, and (5) adjust initial personal opinions. Each discussion section lasted thirty minutes. To strengthen the effectiveness of DBPL for educational topics, a method for generating sociocognitive conflict was implemented. Namely, after the participants read the education-related material and the questions, they were not allowed to engage in dialogue with classmates immediately. I asked them to silently reflect and construct initial opinions on the education-related topics. The participants were also encouraged to write down their thoughts in their notebooks. This preparation resulted in sociocognitive conflicts in the subsequent dialogues. I also designed a different seating chart for every week by using random arrangement in a computer. Before conducting DBPL activities, I randomly assigned two or three students to a group and asked them to confirm the DBPL procedures. Thus, the random assignment provided different groups for almost every DBPL activity.

\section{Measurements}

The study assessed the participating students' learning performance to determine the feasibility of the proposed teaching framework. Three measurements were employed to assess the learning effectiveness of the activity for the participants: a quantitative item scale, an open-ended question on learning perceptions and four rounds of paper-and-pencil tests on the educational topics.

\section{Quantitative scale}

The items of the learning perception scale addressed the DBPL activity and the teacher's guidance. Seven items (item01-item07) for measuring the stu- 
dents' perceptions of the DBPL activity included students' critical thinking as well as their learning interest, motivation, curiosity, needs, effectiveness and satisfaction. Additionally, five items (item08-item12) measured students' perceptions of the teacher's instructional demonstrations, including explanation, query, comparison and reconstruction. These items were formulated based on the reviewed literature. All items are presented in Table 1. The items were formatted into a questionnaire and evaluated according to a 5-point Likert scale, ranging from 1 for 'strongly disagree' to 5 for 'strongly agree'. Three experts in the field of in-service teacher education were consulted to confirm the content validity of the developed instrument. The experts' suggestions were reviewed, and the questionnaires were revised accordingly and then employed to collect data regarding learning perceptions.

\section{Open-ended question on learning perceptions}

An open-ended question was included in the questionnaire following the learning perception scale to collect further data on students' reflections on the DBPL activity. A total of eighteen students responded to this optional open-ended question. All participants were invited to fill in the survey during the sixteenth week of the course after all DBPL activities and tests had been completed. The respondents were not required to write down their names or academic departments on their responses. To maintain anonymity, a randomly chosen student assisted in retrieving the questionnaires. This method can be used to avoid the potential of students of being inclined to give positive feedback to teachers.

\section{Paper-and-pencil tests regarding the education-related topics}

Four learning assessments regarding the eight education-related topics were designed and administered to confirm the participants' comprehension of the education-related topics. Each assessment comprised five items that were formulated as multiple-choice questions. After two rounds of the DBPL activity had been completed, one of the learning assessments was administered in the subsequent week. Each test featured ten items related to two educational topics. For example, the materials for the lesson regarding curriculum ideology included the following description: 'Curriculum ideologies are defined as beliefs about what schools should teach, for what ends and for what reasons (Eisner 2001: 47). Several lessons in a specific textbook featured a gender stereotype that a mother is busy cooking in the kitchen while a father is just sitting on a sofa and reading his newspapers'. The corresponding test 
question was: 'Which option among the following depicted in textbooks implies curriculum ideology? A) an aborigine in shabby clothes was often drunk; B) a teacher standing at the front of a classroom; C) a man peddling ice cream on a street corner; D) many people dining in a restaurant'. The correct answer was A. The purpose of this item was to examine the participants' comprehension of curriculum ideology. Theoretically, after the participants extended their understandings of curriculum ideology through the DBPL activity, they would be able to determine which option was correct.

\section{Analysis of learning performance levels}

\section{Analysis of learning perception of participants on the DBPL}

The data for learning perceptions on participation in DBPL are presented in Table 1. The mean scores were 4.14-4.73, and standard deviation was $0.465-0.837$. As denoted in Table 1, all item scores were greater than 4 , indicating that the students reported high learning perceptions for their participation in the DBPL activity.

The student teachers reported positive perceptions of their participation in the DBPL activity. Specifically, for the sixth item about critical thinking skills, the majority of the participants perceived that the DBPL activity benefited their analysis and critical thinking skills. Satisfaction of learning needs corresponded with the lowest score for all the items and therefore requires further attention.

As mentioned in the literature review, university students have sometimes avoided engaging in peer discussions. The students' experiences of participating in DBPL activities may have been insufficient. These students were qualified and able to be teachers; thus, education-related topics incited their curiosity and motivation to learn and comprehend. In their original opinions on education-related topics, they may have maintained a single or surface-level viewpoint. When the students listened to different viewpoints from peers during the DBPL activity and considered details they had previously neglected, they may engage in intense psychological processes. The student teachers recognised that the DBPL activity and cognitive processes prompted them to consider multiple viewpoints, and that these perspectives benefited them when they encountered educational problems. The score for satisfaction of learning needs was lower than those of other items; therefore, a few responses to the open-ended question are presented for discussion in the following section. 
Table 1. Summary of learning perceptions regarding participation in DBPL

\begin{tabular}{|c|c|c|c|c|c|c|c|}
\hline \multirow[b]{2}{*}{ Items } & \multicolumn{5}{|c|}{ Number } & \multirow[b]{2}{*}{$M$} & \multirow[b]{2}{*}{$S D$} \\
\hline & $\mathrm{SD}$ & $\mathrm{D}$ & $\mathrm{N}$ & $\mathrm{A}$ & SA & & \\
\hline $\begin{array}{l}\text { The DBPL activity stimulated my interest } \\
\text { in education-related topics. }\end{array}$ & 0 & 3 & 8 & 51 & 53 & 4.34 & 0.724 \\
\hline $\begin{array}{l}\text { The DBPL activity increased my motivation } \\
\text { to investigate education-related topics. }\end{array}$ & 0 & 1 & 4 & 52 & 58 & 4.45 & 0.610 \\
\hline $\begin{array}{l}\text { The DBPL activity increased my curiosity } \\
\text { about education-related topics. }\end{array}$ & 1 & 1 & 8 & 32 & 73 & 4.52 & 0.742 \\
\hline $\begin{array}{l}\text { The DBPL activity was suited to my needs } \\
\text { in learning about education-related topics. }\end{array}$ & 1 & 3 & 4 & 41 & 66 & 4.46 & 0.764 \\
\hline $\begin{array}{l}\text { The DBPL activity enhanced my process of } \\
\text { learning about education-related topics. }\end{array}$ & 0 & 6 & 7 & 49 & 53 & 4.30 & 0.805 \\
\hline $\begin{array}{l}\text { The DBPL activity stimulated my critical } \\
\text { thinking. }\end{array}$ & 0 & 0 & 1 & 29 & 85 & 4.73 & 0.465 \\
\hline The DBPL activity satisfied my learning needs. & 0 & 4 & 16 & 55 & 40 & 4.14 & 0.782 \\
\hline $\begin{array}{l}\text { The teacher provided adequate guidance for } \\
\text { our discussions of education-related topics. }\end{array}$ & 0 & 1 & 15 & 39 & 60 & 4.37 & 0.743 \\
\hline $\begin{array}{l}\text { The teacher provided adequate explana- } \\
\text { tions that advanced my comprehension of } \\
\text { education-related topics. }\end{array}$ & 0 & 0 & 11 & 47 & 57 & 4.40 & 0.660 \\
\hline $\begin{array}{l}\text { The teacher's demonstration of relevant skills } \\
\text { raised my confidence in critical thinking in } \\
\text { DBPL-activity participation. }\end{array}$ & 0 & 2 & 13 & 58 & 42 & 4.22 & 0.711 \\
\hline $\begin{array}{l}\text { The teacher presented methods that enhanced } \\
\text { my learning effectiveness in the DBPL activity. }\end{array}$ & 0 & 1 & 4 & 40 & 70 & 4.56 & 0.610 \\
\hline I performed well in all the DBPL activities. & 1 & 3 & 17 & 49 & 45 & 4.17 & 0.837 \\
\hline
\end{tabular}

Note: $\quad \mathrm{SD}=$ Strongly Disagree, $\mathrm{D}=$ Disagree, $\mathrm{N}=$ Neutral, $\mathrm{A}=$ Agree, $\mathrm{SA}=$ Strongly Agree,

Teachers should guide the dialogue processes in DBPL activities and should demonstrate suitable practices for peer dialogue. In the present study, DBPL for stimulating cognitive processes was based a procedure of reading, formulating, expressing and listening, asking and responding and adjusting. Following teachers' explanations and demonstrations in each phase, participants' cognitive abilities were activated. In particular, in the expressing and listening phase, cognitive conflict was generated, which may have motivated subsequent querying and self-regulation of viewpoints. The step-by-step guidance enhanced participants' engagement in cognitive processes. Consequently, the participants reported positive impressions of the instructors' 
guidance in the DBPL activity. Based on the participants' perceptions of the DBPL activity and of the teachers' demonstrations, the present study determined that the DBPL framework facilitated the participation of the student teachers in discussions on education-related topics.

\section{Analysis of learning perception in responses to the open-ended question}

According to the analysis of the eighteen responses to the open-ended question, four themes were identified. Of the eighteen respondents, eight perceived benefits from the DBPL activity in their learning of education-related topics. They expressed that DBPL helped them produce advanced opinions after listening to various opinions from peers. The following are responses from two students:

In the DBPL activity, I found my partner's opinion differed from mine. I integrated my thoughts and his opinions and constructed a new idea to comprehend the educational topics. This learning activity really extended my perspectives on some specific educational topics (SO4).

I valued the DBPL activity because the activity prompted me to rethink my ideas about education and strategies related to educational topics. I cannot help but say that through DBPL I came to understand educational practices better than ever (S12).

Four respondents expressed that they had realised flaws in their initial opinions after comparing their ideas with the opinions of peers after the DBPL activity. One student wrote, 'Initially, I was confident in my thoughts on education-related topics. Nevertheless, I had to admit that my initial thoughts were insufficient in addressing the education-related topics when I listened to my partner's opinions' (SO6). These responses retrieved from six participants revealed that participants benefited from the DBPL activity, and specifically verified that the DBPL activity deepened the participants' comprehension of the education-related topics.

Another four respondents expressed that they lacked sufficient critical thinking skills to engage in dialogue with their peers. One of the four respondents wrote, 'I always felt that I could not deeply analyse the educationrelated topics or reasonably evaluate the value of my partner's opinions. I expressed only a few short sentences when discussing with peers' (SO9). Two respondents indicated that their partners lacked critical thinking skills. One of the two respondents wrote, 'My random partner did not understand 
the full meanings of the education-related topics and insisted on his/her inadequate opinions, so the dialogue bothered me. I felt a barrier when conversing with my partners' (SO5).

According to the cited literature, critical thinking comprises the mental processes of conceptualising, applying, analysing, synthesising and evaluating information to reach an answer or conclusion. When learners perceived difficulty in analysing topics, their critical thinking was limited. Moreover, if the participants did not sufficiently read and understand the texts, they experienced barriers in topic analysis, leading to poor critical thinking as well as poor peer dialogue. Additionally, participants who had not formed initial opinions experienced difficulty evaluating peer viewpoints, as mentioned by the quoted respondent. Due to a lack of sociocognitive conflict among a few participants, their partners may have perceived a barrier during the DBPL activity. Sufficient grasp of discussion topics was crucial for the activation of critical thinking and engagement in the DBPL activity.

Analysis and interpretation of the eighteen responses to the open-ended questions revealed that the students not only perceived the usefulness of peer discussions for gaining comprehension of education-related topics but also extended their opinions on educational practices. When the students reformulated their concepts of education through dialogue-based interactions, they were able to increase the complexity of the strategies they used to resolve problems regarding education-related topics. However, based on the study findings regarding insufficient dialogue on the education-related topics, teacher education students should be equipped with skills to comprehend education-related topics and discuss various opinions with peers. If any of the conversation participants in a group understood the topic sufficiently and could express their opinions, the dialogue-based learning was useful to extend education-related opinions though the presentation of different ideas. However, even though the participants were required to complete specific basic disciplines, some students had less pre-existing knowledge that negatively affected the participation in the peer discussions.

\section{Analysis of learning assessments}

The scores for the learning assessments on the education-related topics were calculated, and the number and percentage of each score range are presented in Figure 1. For example, forty-six (40 per cent) students' scores were in the range from 70 to 79 . Additionally, the average score for each test was 66.5 


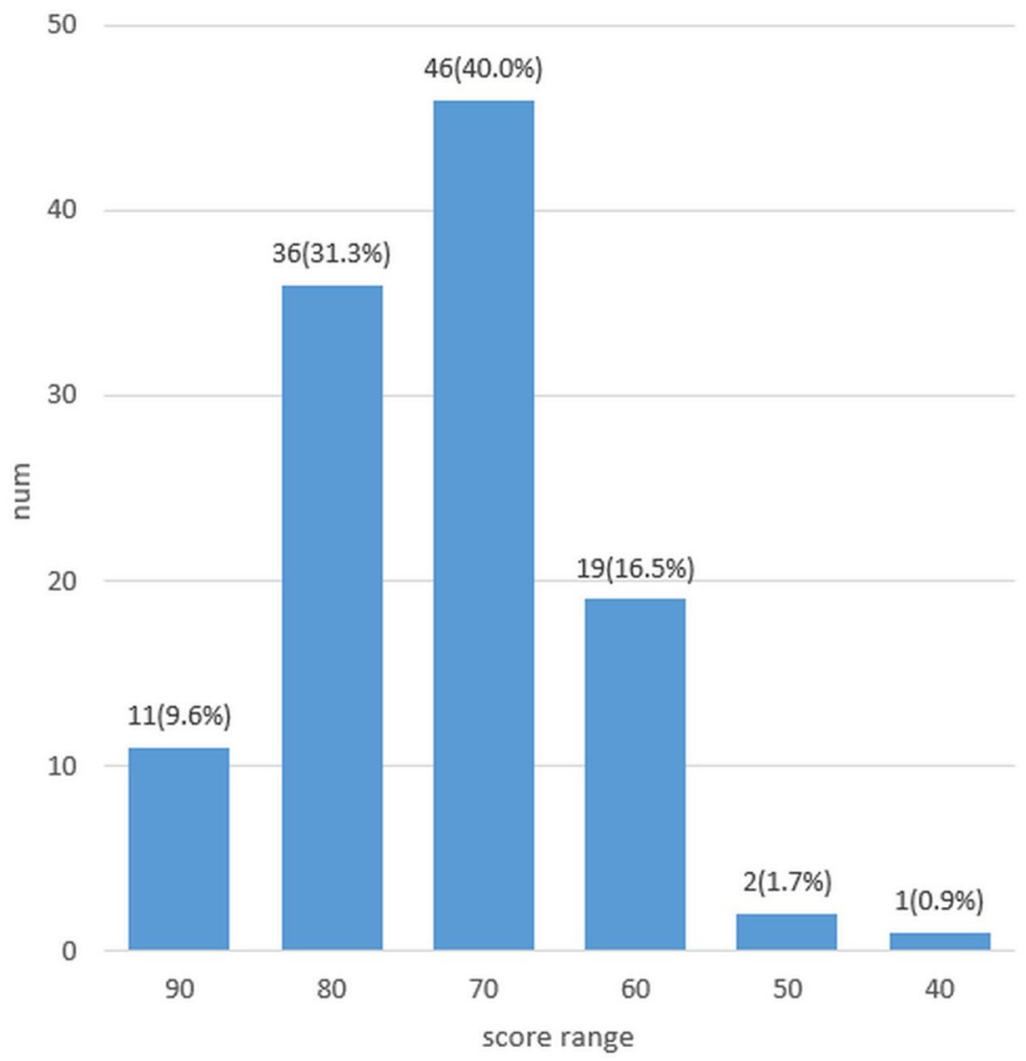

Figure 1. Numbers and mean test scores of the participants

to 83.9. The total average score was 75.1. According to the data presented in Figure 1, more than 97 per cent of the students passed the tests. The scores of nearly 40 per cent of students were over 80 . This result revealed that the DBPL activity could assist the students to comprehend the meaning of educational topics. However, two participants did not pass the test.

As described in the literature, dialogue-based peer interactions and assistance from more knowledgeable peers may enable students to develop more profound comprehension than they could individually. In this study, a learning assessment was designed based on education-related topics and was administered in the weeks following the activity. The participants' acceptable test scores verified that the DBPL activity based on education-related topics enhanced the student teachers' comprehension of educational practices. 


\section{Integrated analysis of the learning performance levels}

The DBPL activity clearly enhanced the participants' understanding of education-related topics. In line with the suggestion of To and Liu (2018), critical thinking processes related to sociocognitive conflict in peer dialogue may have extended the participants' opinions regarding educational practices. Sociocognitive conflict originated from the second and third stages in the DBPL procedure; specifically, these conflicts arose when group members first developed individual opinions and then expressed their opinions among their peers in turns. When the individuals produced their own opinions before conversing with partners, they could logically organise their initial thoughts. Afterwards, the learners could compare their opinions with partners' opinions, reconsider their own opinions, and integrate multiple opinions into a new opinion. This process enabled learners to comprehend the education-related topics more deeply than they had through previous peer dialogues. Moreover, the sixth item of the questionnaire received the highest score among all items, revealing that the participants perceived they had engaged with critical thinking processes. Most of the participants experienced rigorous critical thinking and may have reconsidered the core ideas of the topics; consequently, they achieved acceptable test scores in learning assessments. This result agreed with the perspective of Cantrell (2002): the clearly structured discussion activity not only improved the quality of discussion but also promoted the construction of knowledge.

In addition to the benefits of peer interactions for learning and comprehension of educational topics, the phenomenon of low satisfaction as well as low test scores associated with a few students should be investigated. According to the analysis of responses to the open-ended question, four participants expressed that a lack of critical thinking skills inhibited their abilities to converse with partners, and one participant indicated that their partner did not exhibit critical thinking skills in the DBPL activity. The quantitative data in Table 1 regarding learning perceptions also indicate a relatively low learning satisfaction for peer interactions. Partner assignment should not have been a problem because the assignments of dialogue partners were different each week. The lack of pre-existing knowledge on education-related topics during peer discussion (Guilford 2001) and lack of critical thinking skills (Huang et al. 2017) could have been barriers. These barriers may have resulted in low test scores as well as low satisfaction with peer discussions in the relevant cases. The respondents indicated that they could not deeply analyse the 
education-related topics or reasonably evaluate their partners' opinions. The first phase of the processes related to critical thinking in the present study was reading the texts on the assigned topics. For participants who did not understand the central ideas of the topics from reading, lack of pre-existing knowledge may have caused these results. Moreover, lack of pre-existing knowledge of the topics may also have contributed to some participants' difficulty in evaluating their partners' opinions. Generally, evaluation involves a comparison between an individual's own opinions and their partners' opinions. In this study, students who did not generate their own viewpoints due to a lack of pre-existing knowledge could not engage in comparisons of conflicting views. Consequently, some students obtained low test scores and reported low satisfaction with the DBPL activity.

Although the students who enrolled in the course analysed in this study were presumed to be prepared with a certain level of knowledge to discuss the education-related topics, differences in the levels of comprehension of the topics among the participants were evident. Insufficient pre-existing knowledge of the education-related topics affected reading comprehension on the texts (Scheiter et al. 2014) and reading comprehension related to critical thinking skills (Huang et al. 2017); thus, insufficient pre-existing knowledge of educational topics was a barrier that affected critical thinking skills during the DBPL activity in the relevant cases. In this study, the student teachers were assumed to have pre-existing knowledge that they could apply in discussions of the educational topics. However, there may have been substantial difference in their learning outcomes from previous courses, resulting in poor discussions among some of the student teachers. This study supported the perspectives of Guilford (2001) and Scheiter et al. (2014): pre-existing knowledge of education-related topics was critical in the peer discussions. Additionally, based on the participants' performances, this study showed the feasibility of the DBPL activity under the teachers' guidance with a focus on critical thinking processes.

\section{Conclusions and implications for teaching practices}

Based on my experiences teaching educational practices, I constructed a course framework involving DBPL to improve student teachers' critical thinking skills and promote their comprehension of education-related topics. This study also evaluated the feasibility of the teaching framework by assessing the learning performance levels of the participating students. The contents 
of the course Curriculum Development and Design provided a diversity of ideology and various opinions, facilitating students' discussion among themselves. According to the study findings, the majority of my students performed well on the tests and perceived the benefits of DBPL for comprehension and critical thinking on education-related topics. Thus, this teaching activity achieved the learning objective of the course. The study revealed that the proposed framework of DBPL is a feasible and useful teaching strategy for university classes.

To advance students' knowledge, learning activities involving peer discussion are often employed in many disciplines of higher education. However, problems may occur if instructors do not design the teaching procedures according to social interaction theory. The most suitable teaching procedure for guiding peer interaction mainly focuses on managing sociocognitive conflict among peers. Sociocognitive conflict in critical thinking processes is key to positive learning outcomes. In this study, reading about education-related topics and producing initial opinions before conversing with partners were crucial steps, because the formation of initial personal opinions laid the foundation for sociocognitive conflict, which resulted in reconsideration of ideas.

Pre-existing knowledge of the discussed topics and problems regarding critical thinking skills may also affect the results of DBPL activities. In this study, students' levels of pre-existing knowledge regarding education-related topics affected their comprehension of the texts, thereby affecting critical thinking skills. Teachers should be aware of students' levels of comprehension and infer their levels of knowledge on the discussion issues accordingly. An increase in awareness of students' pre-existing knowledge would enable more strategic partner assignment for enhanced peer discussion.

Critical thinking skills for education-related topics are worthy of attention. Although the majority of the students perceived the benefits of DBPL in learning effectiveness on education-related topics and considered it a useful method for gaining critical thinking skills, a few students reported that their critical thinking skills were insufficient. Critical thinking involves using objective analysis to form a judgment based on multiple ideas, and this skill helps students acquire knowledge, strengthen arguments and address social problems. If students lack sufficient knowledge to evaluate educationrelated topics, their opinions may be limited. Thus, when teachers design DBPL activities, students should be prepared with knowledge regarding the issues under discussion before peer interactions. Teachers should also give clear instructions about the process of peer dialogue and train students in 
critical thinking skills. This study also clarified why teacher-provided demonstrations of sociocognitive processes benefited the student teachers' critical thinking.

Shih-Hsiung Liu is a Professor at National Changhua University of Education, Taiwan. He earned his Ph.D. in integrating technology into instruction from National Ping-Tung University of Education in Taiwan in 2005. Prior to working at university, he had been a primary school teacher for seventeen years. He specialises in pre-service and in-service teacher education, especially for technology integration during instruction. He has published many articles in a number of professional journals. Additionally, he has often been invited to mentor in-service teachers in professional development. He is currently interested in collaborative learning in improving classroom teaching practices.

\section{References}

Andersen, E., L. Olsen, J. Denison, I. Zerin and M. Reekie (2018), “'I will go if I don’t have to talk": Nursing students' perceptions of reflective, debriefing discussions and intent to participate', Nurse Education Today 70: 96-102. https://doi.org/10.1016/ j.nedt.2018.08.019.

Berne, J. I., and K. F. Clark (2008), 'Focusing literature discussion groups on comprehension strategies', Reading Teacher 62, no. 1: 74-79. https://doi.org/10.1598/RT.62.1.9.

Beyer, B. K. (1995), Critical Thinking (Bloomington, IN: Phi Delta Kappa Educational Foundation).

Bohm, D., D. Factor and P. Garrett (1991), Dialogue-A Proposal, http://www.david-bohm. net/dialogue/dialogue_proposal.html.

Bridges, D. (1990), 'The character of discussion: A focus on students', in W. Wilen (ed.), Teaching and Learning through Discussion (Springfield, IL: Thomas), 97-112.

Brookfield, S. (2012), Teaching for Critical Thinking: Tools and Techniques to Help Students Question their Assumptions (San Francisco, CA: Jossey-Bass).

Buchs, C., C. Pulfrey, F. Gabarrot and F. Butera (2010), 'Competitive conflict regulation and informational dependence in peer learning', European Journal of Social Psychology 40, no. 3: 418-435. https://doi.org/10.1002/ejsp.631.

Butera, F., and C. Darnon (2010), 'Socio-cognitive conflict and learning: Past and present', Proceedings of the 9th International Conference of the Learning Sciences 2: 212-213. 
Cantrell, S. C. (2002), 'Promoting talk: A framework for reading discussions in teacher education courses', Journal of Adolescent \& Adult Literacy 45, no. 7: 642-651.

Chou, C. and P. Lin (2015), 'Promoting discussion in peer instruction: Discussion partner assignment and accountability scoring mechanisms', British Journal of Educational Technology 46, no. 4: 839-847. https://doi.org/10.1111/bjet.12178.

Ding, L., E. Er and M. Orey (2018), 'An exploratory study of student engagement in gamified online discussions', Computers \& Education 120: 213-226. https://doi.org/ 10.1016/j.compedu.2018.02.007.

Dixon-Krauss, L. A. (1995), 'Partner reading and writing: Peer social dialogue and the zone of proximal development', Journal of Reading Behavior 27, no. 10: 45-63.

Doise, W. and G. Mugny (1984), The Social Development of the Intellect (Oxford: Pergamon Press).

Eisner, E. (2001), The Educational Imagination: On the Design and Evaluation of School Programs, 3rd ed., (Upper Saddle River, NJ: Prentice Hall).

Guilford, W. (2001), 'Teaching peer review and the process of scientific writing', Advances in Physiology Education 25, no. 3: 167-175. https://doi.org/10.1152/ advances.2001.25.3.167.

Hammond, J. A., C. P. Bithell, L. Jones and P. Bidgood (2010), 'A first-year experience of student-directed peer-assisted learning', Active Learning 11, no. 3: 201-212. https:// doi.org/10.1177/1469787410379683.

Hendriks, V. and D. Maor (2004), 'Quality of students' communicative strategies delivered through computer-mediated communication', Journal of Interactive Learning Research 15, no. 1: 5-32.

Huang, M. Y., H. Y. Tu, W. Y. Wang, J. F. Chen, Y. T. Yu and C. C. Chou (2017), 'Effects of cooperative learning and concept mapping intervention on critical thinking and basketball skills in elementary school', Thinking Skills and Creativity 23: 207-216. https://doi.org/10.1016/j.tsc.2017.01.002.

Killen, R. (2000), Teaching Strategies for Outcome-based Education (Lansdowne: Juta and Co Ltd).

King, A. (2002), 'Structuring peer interaction to promote high-level cognitive processing', Theory into Practice 41: 33-40. https://doi.org/10.1207/s15430421tip4101_6.

McMahon, S. I., and T. E. Raphael (1997), 'The book club program: Theoretical and research foundations', in S. I. McMahon, T. E. Raphael, V. Goatley and L. Pardo (eds.) The Book Club Connection (New York: Teachers College Press), 3-25.

Michaels, S., M. C. O’Connor, M. W. Hall and L. B. Resnick (2010), Accountable Talk Sourcebook: For Classroom Conversation that Works (Pittsburgh, PA: University of Pittsburgh Institute for Learning).

Mogonea, F., and A. M. Popescu (2015), 'The role of sociocognitive conflict in academic-type learning', Procedia-Social and Behavioral Sciences 180: 865-870. https://doi.org/ 10.1016/j.sbspro.2015.02.228. 


\section{Shih-Hsiung Liu}

Mugny, G., and W. Doise (1978), 'Socio-cognitive conflict and the structure of individual and collective performances', European Journal of Social Psychology 8: 181-192.

Piaget, J. (1975), The Equilibration of Cognitive Structures: The Central Problem of Intellectual Development (Chicago, IL: University of Chicago Press).

Posner, G. J., K. A. Strike, P. W. Hewson and W. A. Gertzog (1982), 'Accommodation of a scientific conception: Toward a theory of conceptual change', Science Education 66, no. 2: 211-227. doi:10.1002/sce.3730660207.

Rogoff, B. (1990), Apprenticeship in Thinking: Cognitive Development in Social Context (New York: Oxford University Press).

Ryan, R. M. and E. L. Deci (2000), 'Intrinsic and extrinsic motivations: Classic definitions and new directions', Contemporary Educational Psychology 25: 54-67. https://doi.org/ 10.1006/ceps.1999.1020.

Sambell, K., S. Brown and L. Graham (2017), Professionalism in Practice: Key Directions in Higher Education Learning, Teaching and Assessment (London: Palgrave).

Scheiter, K., A. Schüler, P. Gerjets, T. Huk and F. W. Hesse (2014), 'Extending multimedia research: How do prerequisite knowledge and reading comprehension affect learning from text and pictures?', Computers in Human Behavior 31: 73-84. https://doi.org/ 10.1016/j.chb.2013.09.022.

Schwab, G. (2011), 'From dialogue to multilogue: A different view on participation in the English foreign-language classroom', Classroom Discourse 2: 3-19. https://doi.org/ 10.1080/19463014.2011.562654.

Scriven, M. and R. Paul (n.d.), Defining Critical Thinking, https://www.criticalthinking.org/ pages/defining-critical-thinking/766.

Sohmer, R., S. Michaels, M. C. O'Connor and L. Resnick (2009), 'Guided construction of knowledge in the classroom', in B. Schwarz, T. Dreyfus and R. Hershkowitz (eds), Transformation of Knowledge through Classroom Interaction (New York: Taylor \& Francis), 105-129.

Soter, A. O., I. A. Wilkinson, K. Murphy, L. Rudge, K. Reninger and M. Edwards (2008), 'What the discourse tells us: Talk and indicators of high-level comprehension', International Journal of Educational Research 47: 372-391. https://doi.org/10.1016/ j.ijer.2009.01.001.

Taal, M., and L. Oppenheimer (1989), 'Socio-cognitive conflict and peer interaction: Development of compensation', European Journal of Social Psychology 19, no. 1: 77-83. https://doi.org/10.1002/ejsp.2420190107.

Tegos, S., and S. Demetriadis (2017), 'Conversational agents improve peer learning through building on prior knowledge', Educational Technology \& Society 20, no. 1: 99-111.

To, J., and Y. Liu (2018), 'Using peer and teacher-student exemplar dialogues to unpack assessment standards: Challenges and possibilities', Assessment \& Evaluation in Higher Education 43, no. 3: 449-460. https://doi.org/10.1080/02602938.2017 .1356907 . 
White, B. A., J. R. Miles, K. A. Frantell, J. T. Muller, L. Paiko and J. LeFan (2019), 'Intergroup dialogue facilitation in psychology training: Building social justice competencies and group work skills', Journal of Diversity in Higher Education 12, no. 2: 180-190. https://doi.org/10.1037/dhe0000089.

Wood, A. K., R. K. Galloway, J. Hardy and C. M. Sinclair (2014), 'Analyzing learning during peer instruction dialogues: A resource activation framework', Physical Review Special Topics-Physics Education Research 10, no. 2: 020107.

Vygotsky, L. S. (1978), Mind and Society: The Development of Higher Mental Processes (Cambridge, MA: Harvard University Press). 